\title{
SÍNTESE, CARACTERIZAÇÃO E AVALIAÇÃO DO PODER ANTIMICROBIANO DO NANOCOMPÓSITO Ag/TiO
}

\section{SYNTHESIS, CHARACTERIZATION AND EVALUATION OF THE ANTIMICROBIAL POWER OF THE Ag/TiO 2 NANOCOMPOSITE}

\author{
M.E.B SOUSA ${ }^{1}$, P.F.R. REMIRO ${ }^{1}$, A. BERNARDO ${ }^{1, *}$ and M.L. AGUIAR ${ }^{1}$ \\ ${ }^{1}$ Federal University of São Carlos, Department of Chemical Engineering, São Carlos, São Paulo, Brazil
}

${ }^{*}$ Corresponding author. Federal University of São Carlos, Department of Chemical Engineering, São Carlos, São Paulo, Brasil, Phone: +55 16 981887837

e-mail address: abernardo@ufscar.br

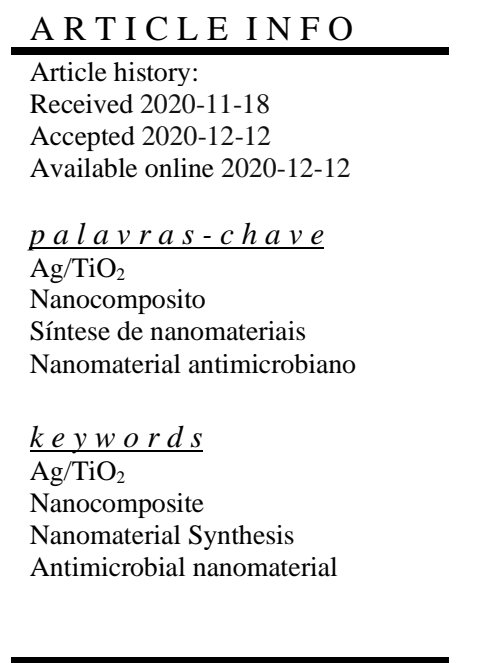

\begin{abstract}
A B S T R A C T
In the last decades, there has been an increase in interest in studies in the field of nanotechnology. These are due to the several advantages and applications that nanomaterials have. Along with advances in research involving nanotechnology, there is a concern with the control of bacteria, fungi, and viruses harmful to human health. A very clear and current example is the Pandemic (COVID-19) that the world is experiencing, which highlights the importance of controlling microorganisms in the atmosphere, water, and soils. Among the several materials that have the antimicrobial capacity, are silver and titanium dioxide. In this context, this work aimed to synthesize and characterize Ag/TiO2 nanocomposites by physicalchemical techniques and evaluate them against their antimicrobial power against E.coli microorganisms. S. aureus and C.albicans. Silver nanoparticles were dispersed over a matrix of titanium dioxide, which showed antimicrobial power between 62 and 71\%, demonstrating to be a material with great potential to be used in water and air purifying products.
\end{abstract}

\section{R E S U M O}

Nas últimas décadas houve um aumento no interesse em estudos no campo da nanotecnologia, $e$ isso se deve às diversas vantagens e aplicações que os nanomateriais apresentam. Juntamente com o avanço nas pesquisas envolvendo a nanotecnologia, está a preocupação com o controle de bactérias, fungos e vírus danosos à saúde humana. Um exemplo bastante claro e atual é a Pandemia (COVID-19) que o mundo está vivenciando, a qual ressalta a importância do controle de microorganismos existentes na atmosfera, água e solos. Dentre os inúmeros materiais que apresentam capacidade antimicrobiana, estão a prata e o dióxido de titânio. Nesse contexto, este trabalho teve como proposta sintetizar e caracterizar nanocompósitos de Ag/TiO2 por técnicas físico-químicas e avaliá-los em relação ao poder antimicrobiano frente aos microrganismos E.coli. S. aureus e C.albicans. Formaram-se nanopartículas de prata dispersas sobre uma matriz de dióxido de titânio, os quais apresentaram poder antimicrobiano entre 62 e $71 \%$ demonstrando ser um material com um grande potencial para ser utilizado em produtos purificadores de água elou ar. 


\section{N O M E N C L A T UR A}

AgNPs Nanopartículas de Prata

D.O. Densidade Óptica

$I_{o} \quad$ Intensidade da luz incidente

I Intensidade da luz transmitida

ROS Espécies reativas de oxigênio

\section{INTRODUÇÃO}

Microrganismos como bactérias, vírus e fungos representam uma grande preocupação à saúde humana. Um exemplo atual e amplamente divulgado é a pandemia no ano de 2020 da COVID-19, doença causada pelo novo coronavírus, que já causou em torno de 1,7 milhões de mortes no mundo (WHO, 2020). Um outro exemplo igualmente preocupante é a resistência aos antimicrobianos. De acordo com um relatório divulgado pela Organização das Nações Unidas, agências internacionais e especialistas, pelo menos 700.000 pessoas morrem a cada ano devido a doenças resistentes a medicamentos antimicrobianos (IAGC, 2019), sendo a prevenção de infecções uma das principais formas de diminuir esses números. Esses cenários deixam bastante clara a necessidade de novas alternativas para o controle de microrganismos presentes na atmosfera, água e solos.

Propriedades antimicrobianas de nanocompósitos de $\mathrm{Ag} / \mathrm{TiO}_{2}$ vêm sendo muito estudadas nos últimos anos. Zawadzka et al. (2016) avaliaram essas propriedades em revestimentos de $\mathrm{AgNPs} / \mathrm{TiO}_{2}$ e demonstraram uma interdependência entre a concentração de prata liberada e a inibição do crescimento da bactéria Staphylococcus aureus. Já Zhang e Chen (2009) relataram uma maior inibição no crescimento de cepas de Escherichia coli quanto menor o tamanho das AgNPs em um ensaio com pó de nanocompósitos de $\mathrm{Ag} / \mathrm{TiO}_{2}$.

Estudos sobre o mecanismo da atividade antibacteriana de íons de prata e nanopartículas de prata mostram que essa propriedade está relacionada com alterações morfológicas e estruturais na célula bacteriana (KHODASHENAS; GHORBANI, 2015). No caso do $\mathrm{TiO}_{2}$, Sunada et al. (2003) estudaram a atividade bactericida de filmes de $\mathrm{TiO}_{2}$ irradiados com luz UV sobre a $E$. coli e propuseram o seguinte mecanismo: desordenamento da membrana exterior da célula da $E$. coli seguido pelo desordenamento da membrana citoplasmática. Esse estudo sugere que a combinação de $\mathrm{TiO}_{2}$ com um reagente antibacteriano que possa atravessar a membrana externa pode resultar em uma atividade bactericida superior àquela encontrada quando utilizado isoladamente.

Maness et al. (1999) propuseram que os ROS (espécies reativas de oxigênio), tais como $\mathrm{OH}-, \mathrm{O}_{2}-$ e $\mathrm{H}_{2} \mathrm{O}_{2}$ gerados na superfície de $\mathrm{TiO}_{2}$, operam em conjunto para atacar fosfolipídios poliinsaturados em E. coli. Metais como a prata podem atuar como catalisadores na produção de ROS (Marambio-Jones e Hoek, 2010).
Alguns autores relatam que a combinação com nanopartículas de prata aumenta expressivamente a atividade fotocatalítica de $\mathrm{TiO}_{2}$ e, sendo assim, nanocompósitos $\mathrm{Ag} / \mathrm{TiO}_{2}$ possuem a vantagem de pronunciar a função antibacteriana do nanomaterial para uma ampla gama de condições de trabalho (ZHAO et al, 1996). A principal vantagem do uso de nanomateriais está relacionada ao tamanho das partículas, pois, por possuírem grandes áreas superficiais, se tornam mais reativas, já que as reações químicas ocorrem nas superfícies das mesmas (EDELSTEIN; CAMMARATA, 1996).

Neste contexto, este trabalho teve como proposta a síntese, caracterização e avaliação do poder antimicrobiano de nanocompósitos de $\mathrm{Ag} / \mathrm{TiO}_{2}$. Para a síntese do nanocompósito, foi desenvolvido um método com base no método sol-gel, a fim de se obter um método simples e reprodutível para a síntese de nanocompósitos estáveis. Por fim, avaliou-se a capacidade antimicrobiana do material sintetizado utilizando três microrganismos que apresentam características distintas (bactéria Gram-positiva, bactéria Gram-negativa e fungo leveduriforme).

\section{MATERIAIS E MÉTODOS}

\subsection{Síntese do nanocompósito}

Pan et al. (2010) propuseram um método para a síntese do nanocompósito $\mathrm{Ag} / \mathrm{TiO}_{2}$ e obtiveram um material que se mostrou estável e que demostrou atividade bactericida contra E. coli, sem a necessidade de exposição à luz ultravioleta. A síntese utilizada neste trabalho foi baseada no método sol-gel descrito por esses autores. No entanto, por esse método, não foi possível a obtenção de um material sólido que apresentasse cristalinidade. Assim, neste trabalho, foi proposta uma adaptação ao acrescentar uma etapa de calcinação, com o objetivo de eliminar toda a matéria orgânica e conferir cristalinidade ao material sintetizado. A síntese foi realizada da seguinte maneira: foram dissolvidos $0,121 \mathrm{~g}$ de nitrato de prata em $30 \mathrm{~mL}$ de água deionizada após a adição de $0,9 \mathrm{~g}$ de goma arábica. A mistura foi aquecida a $60^{\circ} \mathrm{C}$ por $30 \mathrm{~min}$ para promover a completa dissolução do agente dispersante (goma arábica). A solução foi resfriada a temperatura ambiente e foi adicionada gota-a-gota à uma solução de $5 \mathrm{~mL}$ de butóxido de titânio (IV) (de modo que a proporção em mols $\mathrm{Ag} / \mathrm{Ti}=0,05$ ) em 9,6 mL de ácido acético a 16,7 M, sob agitação contínua. O butóxido de titânio em solução sofreu hidrólise e condensação, rota que caracteriza o método sol-gel (KROLOW et al, 2012). A presença do ácido acético teve como objetivo aumentar o tempo de formação do gel (ALMEIDA FILHO, 1998).

O citrato de sódio foi utilizado como agente redutor da prata a uma concentração de $0,4 \mathrm{M}$ e volume de $3,56 \mathrm{~mL}$, o qual foi adicionado à solução sobre vigorosa agitação e misturado por 3 horas a $60^{\circ} \mathrm{C}$. Para evaporar os materiais orgânicos, a solução foi calcinada em uma mufla a $400^{\circ} \mathrm{C}$ por $1 \mathrm{~h}$, a uma razão de aquecimento de $10{ }^{\circ} \mathrm{C} / \mathrm{min}$, em um cadinho de alumina previamente limpo e tratado termicamente. Em seguida, o material foi desaglomerado por moagem em almofariz e foi feito um peneiramento em peneira de malha $200(74 \mathrm{~mm})$ e o cadinho foi colocado novamente na mufla a $900{ }^{\circ} \mathrm{C}$ por mais $2 \mathrm{~h}$. 
A temperatura de calcinação de $900^{\circ} \mathrm{C}$ foi escolhida para garantir a total eliminação da matéria orgânica e para a obtenção de um sólido cristalino de $\mathrm{TiO}_{2}$ na fase rutilo, pois esta fase é termodinamicamente mais estável. Estudos indicam que o dióxido de titânio apresenta mudança estrutural e irreversível da fase metaestável (anatase) para a fase estável (rutilo), com o aumento da temperatura (ZOCCAL, 2010). Saleiro et al. (2010) avaliaram as fases cristalinas do $\mathrm{TiO}_{2}$ em diferentes temperaturas e observaram que a $700^{\circ} \mathrm{C}$, a fase rutilo foi amplamente majoritária, enquanto Zoccal (2010) constatou que nas calcinações de $800^{\circ} \mathrm{C}$ e $900^{\circ} \mathrm{C}$ cessa à formação da fase anatase, tendo-se apenas a formação da fase rutilo, por ser a fase mais estável.

\subsection{Caracterização do nanomaterial}

O nanomaterial sintetizado foi caracterizado morfologicamente por Microscopia Eletrônica de Varredura (MEV) com Espectroscopia por Dispersão de Energia de Raios $\mathrm{X}$ (EDS), utilizando o equipamento FEI Magellan $400 \mathrm{~L}$ do Laboratório de Caracterização Estrutural (DEMa/ UFSCar). Também foram realizadas medidas de Difração de Raios-X (Difratômetro AXS Analytical X - Ray Systems Siemens D 5005), operando com $1600 \mathrm{~W}$ de potência, $40 \mathrm{kV}$ x $40 \mathrm{~mA}$, radiação $\mathrm{Cu}-\mathrm{K}$ alfa, comprimento de onda $\lambda=1.54056 \AA$, inerente ao tubo de cobre. As intensidades obtidas em ângulos 2 $\theta$ com variações de $5^{\circ}$ a $60^{\circ}\left(2^{\circ} / \mathrm{min}\right)$. O objetivo desta análise foi avaliar a estrutura cristalina do material obtido.

\subsection{Microrganismos escolhidos para o teste "in vitro" da capacidade antimicrobiana do nanomaterial}

Os microrganismos escolhidos para avaliar o efeito antimicrobiano do compósito sintetizado foram:

- $\quad$ Escherichia coli (ATCC 11775): Bactéria bacilar Gram-negativa;

- $\quad$ Staphylococcus aureus (ATCC 29213):

Bactéria esférica (do grupo dos cocos), Gram-positiva;

- Candida albicans (Coleção de culturas):

Fungo leveduriforme;

Estes microrganismos foram escolhidos por representarem diferentes tipos de patógenos e por serem comumente encontrados em todos os ambientes, muitas vezes associados a infecções hospitalesres (JACOBS; ALVES, 2014) (LEISER et al, 2007) (ALVES et al, 2012), além de serem amplamente encontrados em pesquisas, sendo uma boa base de comparação. Alguns exemplos são os trabalhos de Sunada et al. (2003), Maness et al. (1999), Zawadzka et al. (2016) e Zhang e Chen (2009).

\subsection{Avaliação do poder antimicrobiano utilizando a técnica de Densidade Ótica}

A avaliação da turbidez de uma cultura microbiana constitui um método indireto utilizado para estimar a concentração celular. Um feixe de luz é focado em uma suspensão microbiana e este é parcialmente desviado (dispersão da luz) pelas células. A porcentagem de luz não desviada (transmitância, T) é medida por um espectrofotómetro. A quantidade de luz que atravessa a suspensão celular é dependente da concentração de células na suspensão, do tamanho destas, do comprimento de onda e da intensidade $\left(\mathrm{I}_{0}\right)$ da luz incidente. Esta densidade ótica foi determinada com base na equação 1 .

$$
\text { D.O. }=\log \left(I_{0} / I\right)
$$

em que $I_{\mathrm{o}}$ é a intensidade da luz incidente e $I$ é a intensidade da luz transmitida através da suspensão de células.

Para avaliar a concentração de microrganismos presente em cada uma das amostras, foi necessário preparar um padrão de Mc Farland. Assim, foram preparadas duas soluções, uma solução de ácido sulfúrico $\left(\mathrm{H}_{2} \mathrm{SO}_{4}\right)$ a $1 \%$ v/v e uma solução de cloreto de bário $\left(\mathrm{BaCl}_{2}\right)$ a $1,175 \% \mathrm{~m} / \mathrm{v}$. O preparo da solução final foi feito adicionando $9,95 \mathrm{~mL}$ da solução de ácido sulfúrico e $0,05 \mathrm{~mL}$ da solução de cloreto de bário a um tubo de $10 \mathrm{~mL}$. Esta solução apresentou uma concentração de $1,5 \times 10^{8} \mathrm{~g} / \mathrm{mL}$. A solução foi armazenada a temperatura ambiente e ao abrigo de luz. O precipitado de sulfato de bário, quando ressuspendido, corresponde à densidade conferida pelo cultivo dos microrganismos em meio líquido, na concentração de $1,5 \times 10^{8}$ UFC/mL na escala Mc Farland (MCFARLAND, 1907)

Para a avaliação do poder antimicrobiano do compósito foram preparados tubos com $15 \mathrm{~mL}$ do meio de cultura Muller Hinton (Peptona de caseína 17,5 g/L; Peptona de carne 2,0 g/L; Amido 1,5 g/L; Ágar 17,0 g/L; Água destilada q.s.p.; pH final $7,3 \pm 0$ ), e nestes foram adicionadas $10^{3}$ células dos microrganismos, $2,5 \mathrm{mg}$ do nanomaterial e $1 \% \mathrm{v} / \mathrm{v}$ do agente dispersante Tween 80 (após a realização do teste de toxicidade). Os tubos foram incubados em estufa a $37^{\circ} \mathrm{C}$ por $24 \mathrm{~h} \mathrm{e}$ posteriormente foram feitas as leituras de densidade óptica. Todos os tubos e demais aparatos foram esterilizados com calor úmido, em autoclave a $121^{\circ} \mathrm{C}$ por $15 \mathrm{~min}$.

O comprimento de onda utilizado foi $625 \mathrm{~nm}$, pois este comprimento de onda é comumente utilizado para medir a Densidade Óptica de suspensões de células de bactérias ou leveduras. Existe, com algumas limitações, uma relação linear entre a Absorbância ou D.O. da cultura e o número total de células por mililitro de suspensão, ou seja, a concentração celular.

Também foram feitos ensaios de controle (tubos contendo o meio de cultura, o microrganismo e o Tween 80) e branco (tubos contendo o meio de cultura e o microrganismo) para garantir a ausência de contaminação e para que houvesse uma referência para a comparação dos dados.

\section{RESULTADOS E DISCUSSÃO}

A Figura 1 apresenta o resultado da caracterização por EDS, que permitiu identificar os elementos químicos presentes na amostra como sendo principalmente titânio, oxigênio e prata, a partir de seus picos característicos. Na Figura 2 estão apresentados os valores correspondentes à concentração normalizada em porcentagem de peso do elemento a qual indica que a maior porcentagem pertence à prata, seguida do titânio. A proporção molar Ag: $\mathrm{TiO}_{2}$ foi de 4,87:95,02, ou seja, $\mathrm{Ag} / \mathrm{TiO}_{2}$ $=0,051$ condizente com a proporção molar utilizada na metodologia $(\mathrm{Ag} / \mathrm{Ti}=0,05)$. 


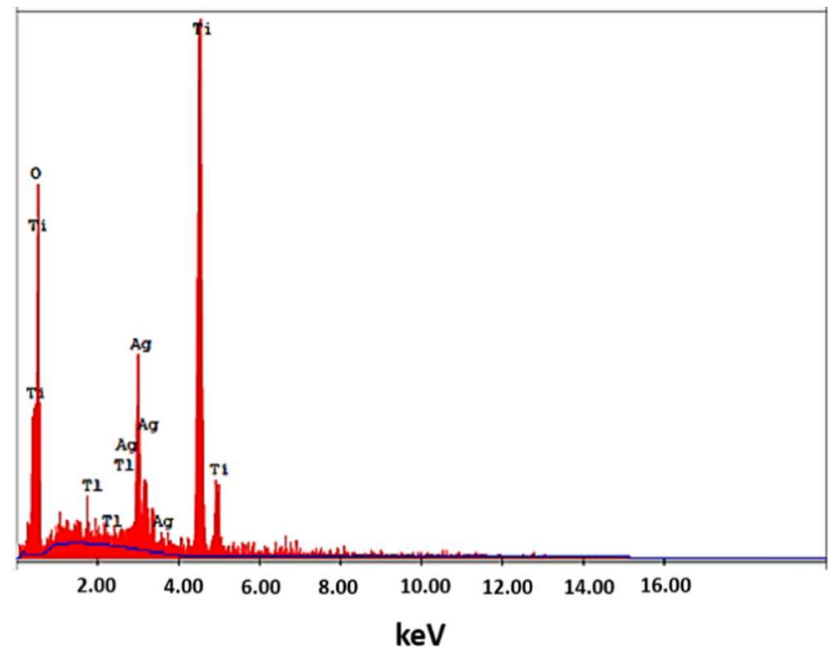

Figura 1 - Espectroscopia por Dispersão de Energia de Raios X (EDS) do nanocompósito $\mathrm{Ag} / \mathrm{TiO}_{2}$ sintetizado.

Tabela 1 - Quantificação normalizada da amostra de Ag/TiO2 pelo EDS.

\begin{tabular}{|ccc|}
\hline Elemento & \% Mássica & \% Atômica \\
\hline O K & 35.45 & 66.21 \\
TlM & 0.77 & 0.11 \\
AgL & 17.57 & 4.87 \\
TiK & 46.2 & 28.81 \\
Total & 100 & 100 \\
\hline
\end{tabular}

O Microscópio Eletrônico de varredura FEI Magellan $400 \mathrm{~L}$ possibilitou avaliar os sólidos em escala nanométrica com boa resolução (magnificação de 30.000 e 120.000 x). Estes resultados estão apresentados nas Figuras 2 e 3. A estrutura de nanocompósitos consiste em uma matriz, que pode ser metálica, cerâmica ou polimérica e que contém o chamado reforço nanométrico (CAMARGO et al, 2009). Na Figura 3, em microescala, o $\mathrm{TiO}_{2}$ parece formar uma matriz, na qual estão dispersas as nanopartículas de prata.

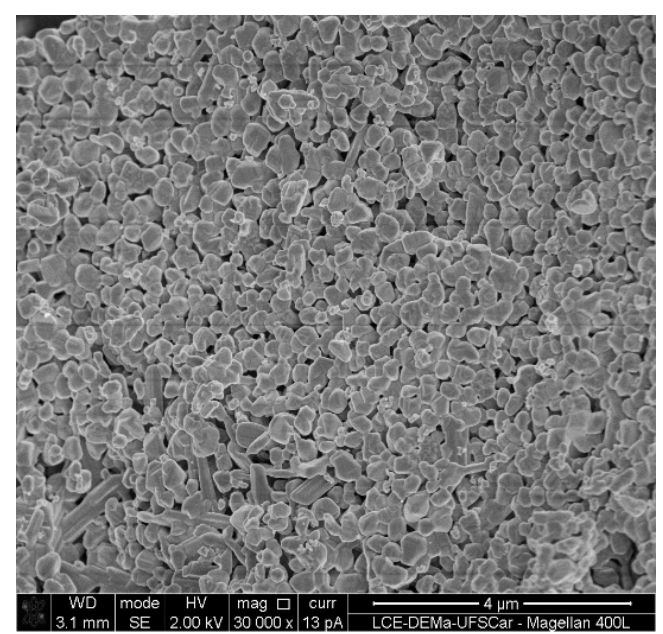

Figura 2 - Microscopia Eletrônica de Varredura (MEV) do nanocompósito $\mathrm{Ag} / \mathrm{TiO}_{2}$ em microescala.

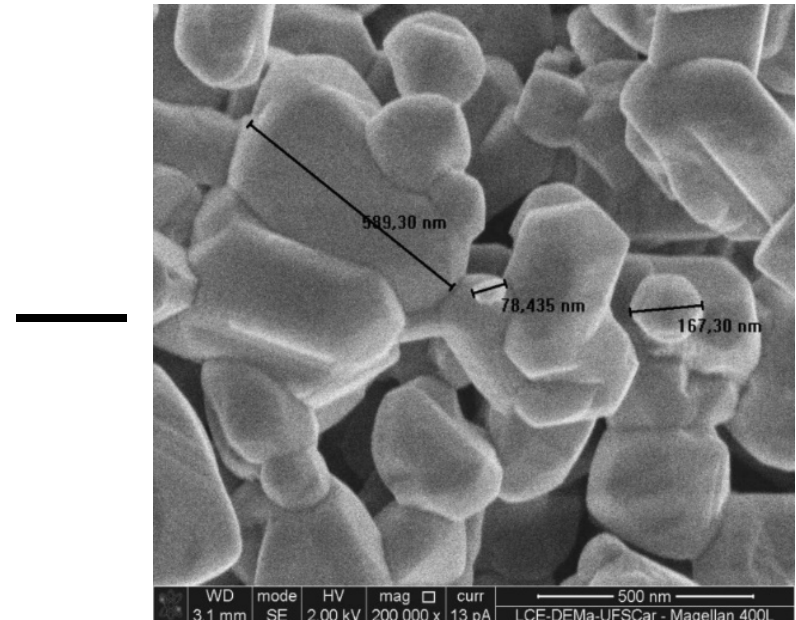

Figura 3 - Microscopia Eletrônica de Varredura (MEV) do nanocompósito $\mathrm{Ag} / \mathrm{TiO}_{2}$ em nanoescala.

As nanopartículas de prata sobre o dióxido de titânio servem como armadilha de elétrons da banda de valência. Dessa forma, mais pares elétrons-buracos ficam disponíveis e, por consequência, mais radicais ativos para catalisar reações de fotodegradação serão formados na superfície da partícula (SÁ, 2017). Na Figura 3, é possível identificar partículas de $\mathrm{Ag} / \mathrm{TiO}_{2}$ com tamanhos em uma faixa de aproximadamente 80 até 600 $\mathrm{nm}$ (tamanhos determinados utilizando-se o programa Image Pro Plus). Desta forma, nota-se que o sólido sintetizado é nanoestruturado e, assim como Costa et al. (2006) observou em seu trabalho, foi observado experimentalmente que os aglomerados de $\mathrm{Ag} / \mathrm{TiO}_{2}$ obtidos são de características moles (formados por forças fracas de Van der Waals), pois são facilmente desaglomerados em almofariz de ágata e passados na malha $200(74 \mu \mathrm{m})$. Este autor não sintetizou compósitos, mas sintetizou nanopartículas cerâmicas de $\mathrm{TiO}_{2}$ que representam a base do compósito sintetizado pelos autores do presente trabalho.

A Figura 4 apresenta o difratograma do compósito $\mathrm{Ag} / \mathrm{TiO}_{2}$ (a) e a comparação com o padrão do programa (b).

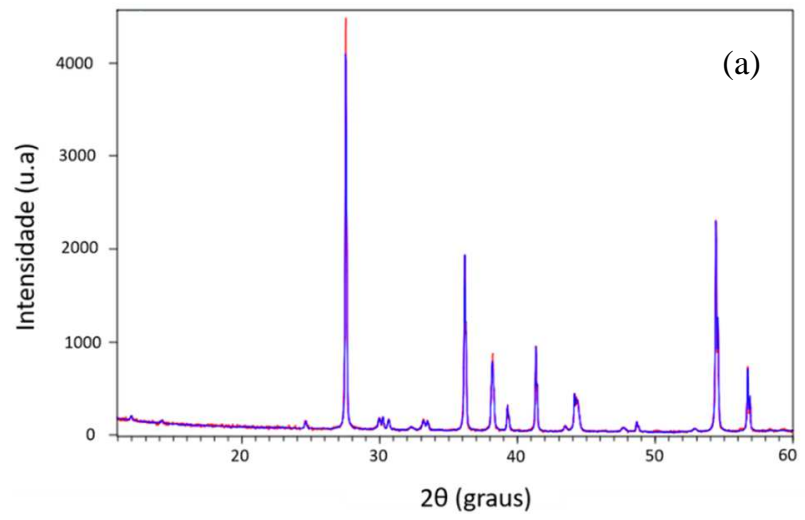




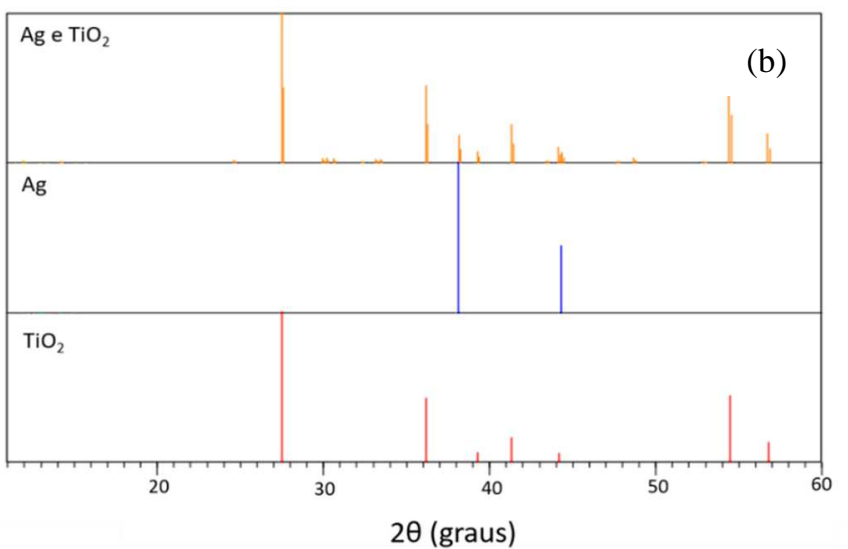

Figura 4 - Difratograma do nanocompósito $\mathrm{Ag} / \mathrm{TiO}_{2}$.

A comparação do difratograma da amostra sintetizada com o banco de dados do programa X'Pert HighScore Plus, considerando os planos de difração, distâncias interplanares e densidade atômica/eletrônica, indicou que o sólido sintetizado é cristalino, com picos correspondentes ao dióxido de titânio na fase do rutilo (mostrado em vermelho) e prata (mostrados em azul). Os picos localizados em 25.4, 37.8, 48.0, 54.5 correspondem aos planos da fase anatase do $\mathrm{TiO}_{2}$ e os localizados em 27.5, 36.1, 54.4, aos da fase rutilo. Possivelmente a presença da fase rutilo está associada a utilização de altas temperaturas de calcinação.

A presença de picos distintos para as duas espécies foi indicativa da presença de ambos os materiais, prata e titânia, característicos de um compósito. Os picos mais intensos da amostra sintetizada corresponderam aos picos mais intensos nos difratogramas padrão de $\mathrm{TiO}_{2}$ e $\mathrm{Ag}$, contudo, caracteriza-se como um compósito.

A Tabela 2 apresenta os dados do poder de inibição dos microrganismos pelo material sintetizado. Analisando essa Tabela, pode-se verificar que o nanocompósito $\mathrm{Ag} / \mathrm{TiO}_{2}$ possui poder antimicrobiano de 67, 62 e 71\% para E.coli, S aureus e C. albicans, respectivamente.

$\mathrm{O}$ nanomaterial foi capaz de inibir os três microrganismos, no entanto, não foi possível inibir em totalidade. Essa inibição parcial pode ter ocorrido devido a escolha da síntese do nanocompósito a alta temperatura $\left(900^{\circ} \mathrm{C}\right)$. A calcinação resultou em $\mathrm{TiO}_{2}$ na fase rutilo e esta fase apresenta menor fotoatividade quando comparada com a fase anatase. A característica de maior fotoatividade da fase anatase se deve à sua maior área de superfície e a menor taxa de recombinação dos pares elétrons-buracos (HASSAN et al, 2016).

A combinação de nanopartículas de prata com dióxido de titânio pode compor compósitos com efeitos fotocatalíticos mais pronunciados, quando comparado ao dióxido de titânio puro (DAHL et al, 2014). Sá (2017) testou a atividade antimicrobiana do nanocompósito e seus resultados sugerem que a síntese do nanocompósito $\mathrm{Ag} / \mathrm{TiO}_{2}$ é uma ótima estratégia para obter um material com efeito fotoativo e antimicrobiano potencializado, utilizável no tratamento de água contaminada por poluentes orgânicos e no combate de infecções causadas por microorganismos $S$. aureus e $M$. bobis.

Neste trabalho foram reiteradas estas ideias e comprovou-se que este compósito é capaz de inibir os três microrganismos estudados. A ação antimicrobiana das AgNPs está ligada a quatro mecanismos bem definidos: (1) adesão de
AgNPs à superfície da parede e membrana celular, (2) penetração de AgNPs no interior da célula causando danos às estruturas intracelulares (mitocôndrias, vacúolos, ribossomos) e biomoléculas (proteínas, lipídios e DNA), (3) AgNPs induziram toxicidade celular e estresse oxidativo causado pela geração de espécies reativas de oxigênio (ROS) e radicais livres, e (4) Modulação de vias de transdução de sinal. Além desses quatro mecanismos bem reconhecidos, as AgNPs também modulam o sistema imunológico das células humanas orquestrando a resposta inflamatória, o que ajuda ainda mais na inibição de microrganismos (TIAN et al, 2007).

Zawadzka et al. (2016) estudaram os mecanismos de ação de $\mathrm{AgNPs} / \mathrm{TiO}_{2}$ contra a bactéria S.aureus utilizando microscópio confocal e Microscopia Eletrônica de Varredura. Os resultados obtidos apontaram para três vias da atividade antibacteriana dos revestimentos testados. A prata liberada pode interagir com enzimas das membranas das células bacterianas e perturbar sua funcionalidade ou penetrar nestas e danificar o DNA. A microscopia de varredura foi utilizada para analisar a topografia das amostras após testes biológicos, bem como observar as alterações morfológicas das células de S. aureus. Os autores concluíram que houve a formação de lacunas na célula bacteriana o que indica um contato direto de AgNPs com as células ocasionado a desintegração das paredes celulares, o que poderia causar a morte celular das bactérias de S. aureus. Assim, a soma dos mecanismos supracitados conferiu ao compósito uma maior eficácia na erradicação de microrganismos, visto que podem apresentar o efeito sinergético. Este efeito ocorre quando os dois materiais agem de maneira independente, mas promovendo a soma dos mecanismos.

\section{CONCLUSÕES}

Este trabalho teve como objetivo a produção de um compósito de prata e dióxido de titânio que apresentasse cristalinidade e capacidade antimicrobiana. Assim, uma adaptação ao método proposto por Pan et al. (2010) para produção de compósito $\mathrm{Ag} / \mathrm{TiO}_{2}$ foi realizada, acrescentando uma etapa de calcinação, com o objetivo de eliminar a matéria orgânica e garantir a cristalinidade. $O$ resultado foi um método simples e facilmente reprodutível. Os resultados da caracterização das amostras pelo MEV com EDS permitiram concluir que foi possível obter nanocompósitos de $\mathrm{Ag} / \mathrm{TiO}_{2}$ pelo método estudado, pois o EDS indicou que a amostra foi constituída principalmente de titânio, oxigênio e prata. Além disso, o MEV indicou partículas de $\mathrm{Ag} / \mathrm{TiO}_{2}$ com tamanhos em uma faixa de aproximadamente 80 até $600 \mathrm{~nm}$ e a formação de nanopartículas de prata dispersas sobre uma matriz de dióxido de titânio. A cristalinidade do material foi indicada pelo Difratograma, com picos correspondentes ao dióxido de titânio na fase do rutilo e à prata. Após a avaliação do poder antimicrobiano concluiu-se que o material produzido inibiu de 62 a $71 \%$ dos microrganismos estudados. Assim, configura-se como um material em potencial para o uso em desinfecção de água e ar, podendo ser aplicado em meios filtrantes. 
Tabela 2: Dados de absorbância média, número de células e porcentagem de inibição dos microrganismos.

\begin{tabular}{|c|c|c|c|c|}
\hline Microrganismo & Nanomaterial & $\begin{array}{l}\text { Absorbância } \\
\text { média }\end{array}$ & $\begin{array}{l}\text { Número de células (comparação } \\
\text { com a solução de McFarland) }\end{array}$ & $\begin{array}{c}\text { Porcentagem de Inibição } \\
(\%)\end{array}$ \\
\hline \multirow{3}{*}{ E.coli } & $\mathrm{Ag} / \mathrm{TiO}_{2}$ & $0,236 \pm 0,001$ & $3,54 \cdot 10^{7}$ & 67,36 \\
\hline & Branco & $0,723 \pm 0,003$ & $1,08 \cdot 10^{7}$ & 0 \\
\hline & Controle & $0,636 \pm 0,003$ & $9,54 \cdot 10^{7}$ & 12,03 \\
\hline \multirow{3}{*}{ S.aureus } & $\mathrm{Ag} / \mathrm{TiO}_{2}$ & $0,163 \pm 0,009$ & $2,5 \cdot 10^{7}$ & 62,33 \\
\hline & Branco & $0,433 \pm 0,008$ & $6,5 \cdot 10^{7}$ & 0 \\
\hline & Controle & $0,427 \pm 0,016$ & $5,92 \cdot 10^{7}$ & 8,9 \\
\hline \multirow{3}{*}{ C.albicans } & $\mathrm{Ag} / \mathrm{TiO}_{2}$ & $0,112 \pm 0,011$ & $1,68 \cdot 10^{7}$ & 71,33 \\
\hline & Branco & $0,391 \pm 0,009$ & $5,87 \cdot 10^{7}$ & 0 \\
\hline & Controle & $0,411 \pm 0,025$ & $6,17 \cdot 10^{7}$ & 4,94 \\
\hline
\end{tabular}

\section{AGRADECIMENTOS}

Os autores gostariam de agradecer o apoio financeiro concedido pela Fundação de Amparo à Pesquisa do Estado de São Paulo (Processo 2014/11425-5), pelo Conselho Nacional de Desenvolvimento Científico e Tecnológico (Processo 139106/2015-4) e pela Coordenação de Aperfeiçoamento de Pessoal de Nível Superior - Brasil (CAPES) - Código de Financiamento 001.

\section{R E F E R Ê N C I A S}

ALMEIDA FILHO, C. Síntese de Materiais via Sol-Gel Casos: Titanato de Alumínio e Alumina Ativada. 1998. 113 p. Dissertação (Mestrado em Engenharia Química). Universidade Federal de Santa Catarina, Florianópolis, 1998.

ALVES L. N. S; OLIVEIRA C. R.; SILVA L. A. P.; GERVÁSIO S. M. D.; ALVES S. R.; SGAVIOLI G. M. Hemoculturas: estudo da prevalência dos microrganismos e o perfil de sensibilidade dos antibióticos utilizados em Unidade de Terapia Intensiva. J Health Sci Inst. São Paulo, v. 30, n. 1, p. 44-47, 2012.

CAMARGO, P. H. C.; SATYANARAYANA, K. G.; WYPYCH, F. Nanocomposites: synthesis, structure, properties and new application opportunities. Mat. Res., São Carlos, SP, v.12, n.1, p.1-39, mar. 2009.

COSTA, A. C. F. M., VILAR, M. A., LIRA, H. L., KIMINAMI, R. H. G. A., \& GAMA, L. Síntese e caracterização de nanopartículas de TiO2. Cerâmica, São Paulo , v. 52, n. 324, p. 255-259, dez. 2006.

DAHL M., LIU Y., YIN Y. Composite Titanium Dioxide Nanomaterials. Chem. Rev., California,114, p 98539889, 2014
EDELSTEIN, A.S.; CAMMARATA, R.C. Nanomaterials: synthesis, properties, and applications. 1 ed. Londres: Taylor and Francis, 1996, 596 p.

HASSAN, M.; ZHAO, Y. P.; XIE, B. Employing TiO2 photocatalysis to deal with landfill leachate: Current status and development. Chemical Engineering Journal, Holanda, v. 285, p. 264-275, 2016.

IAGC - Interagency Coordination Group on Antimicrobial Resistance. No Time to Wait: Securing the future from drug-resistant infections: Report to the SecretaryGeneral of the United Nations. Geneva: United Nations (UN), 2019.

JACOBS, C.; ALVES, I. A. Identificação de microrganismos veiculados por vetores mecânicos no ambiente hospitalar em uma cidade da região noroeste do estado Rio Grande do Sul. Epidemiol Control Infect. Rio Grande do Sul, v. 4, n. 4, p. 238-242, 2014.

KHODASHENAS, B.; GHORBANI, H. R. Synthesis of silver nanoparticles with different shapes. Arabian Journal of Chemistry, Arábia Saudita, v.12, n.8, p. 1823-1838, 2019.

KROLOW, M.Z. et al. Synthesis and Characterisation of Carbon Nanocomposites. In: AVELLANEDA, C. (Ed.). NanoCarbon 2011, Carbon Nanostructures. Berlim: Springer Science \& Business Media; 2012. v. 3, p. 3347.

LEISER, J. J.; TOGNIM, M. C. B.; BEDENDO, J. Infecções hospitalares em um centro de terapia intensiva de um hospital de ensino no norte do Paraná. Ciência, Cuidado E Saúde, Maringá, PR, v.6, n.2, p. 181-186, 2007.

MANESS, P. C., SMOLINSKI, S., BLAKE, D. M., HUANG, Z., WOLFRUM, E. J., \& JACOBY, W. A. Bactericidal activity of photocatalytic $\mathrm{TiO}(2)$ reaction: toward an understanding of its killing mechanism. Appl. Environ. Microbiol., Washington, DC, v.65, n.9, p.4094-4098, 1999.

MARAMBIO-JONES, C. M.; HOEK, E. M. V. A review of the antibacterial effects of silver nanomaterials and potential implications for human health and the environment. 
Journal of Nanoparticle Research, Holanda, v. 12, n. 5, p. 1531-1551, 2010.

MCFARLAND J. The nephelometer: an instrument for estimating the number of bacteria in suspensions used for calculating the opsonic index and for vaccines. $\mathbf{J}$. Am. Med. Assoc. Estados Unidos, v.49, n. 14, p. 1176$1178,1907$.

PAN, X.; Medina-Ramirez, I.; Mernaugh R., Liu, J. Nanocharacterization and bactericidal performance of silver modified titania photocatalyst. Colloids and Surfaces B: Biointerfaces, Holanda, v. 77, n. 1, p. 8289, 2010.

SÁ, F. C. Síntese de nanocompósitos de Eudragit L100/prata-dióxido de titânio (EDGT/Ag-TiO2), degradação fotocatalítica de rodamina b e atividade antibacteriana. Dissertação de Mestrado. Universidade Federal do Vale do São Francisco. Juazeiro, BA, 2017.

SALEIRO, G. T; CARDOSO, S. L; TOLEDO, R and HOLANDA, J. N. F. Avaliação das fases cristalinas de dióxido de titânio suportado em cerâmica vermelha. Cerâmica, São Paulo, v. 56, p. 162-167, 2010.

SUNADA, K.; WATANABE, T.; HASHIMOTO, K. Studies on photokilling of bacteria on $\mathrm{TiO} 2$ thin film. Journal of Photochemistry and Photobiology A: Chemistry, Holanda, v. 156, n. 1-3, p. 227-233, 2003.

TIAN J., WONG K.K., HO C.M., LOK C.N., YU W.Y., CHE C.M., CHIU J.F., TAM P.K. Topical delivery of silver nanoparticles promotes wound healing.
ChemMedChem, Alemanha, v.2, n.7, p. 129-36, jan 2007.

WHO - World Health Organization. WHO Coronavirus Disease (COVID-19) Dashboard. Geneva: World Health Organization (WHO). Disponível em: https://covid19.who.int/. Acesso em: 26 nov. 2020.

ZAWADZKA, K., KISIELEWSKA, A., PIWOŃSKI, I. KADZIOŁA K., FELCZAK A., RÓZALSKA S., WRONSKA N., LISOWSKA K. Mechanisms of antibacterial activity and stability of silver nanoparticles grown on magnetron sputtered $\mathrm{TiO} 2$ coatings. Bull Mater Sci, Alemanha, v.39, p. 57-68, 2016.

ZHANG, H.; CHEN, G. Potent Antibacterial Activities of $\mathrm{Ag} / \mathrm{TiO} 2$ Nanocomposite Powders Synthesized by a One-Pot Sol-Gel Method. Environmental Science \& Technology, Estados Unidos, v. 43, n. 8, p. 2905-2910, mar. 2009.

ZHAO, G.; KOZUKA, H.; YOKO, T. Sol-gel preparation and photoelectrochemical properties of $\mathrm{TiO} 2$ films containing Au and Ag metal particles. Thin Solid Films, Holanda, v. 277, n. 1, p. 147-154, 1996.

ZOCCAL, J. V. M. Síntese e caracterização de nanopartículas de $\mathrm{TiO2}$ pelo método do precursor polimérico. Dissertação (Mestrado em Engenharia Química) - Universidade Federal de São Carlos, São Carlos, 2010. 